\title{
La Centralidad del Protagonista en Al filo del agua
}

Cundo se nos presenta don Dionisio Maria Martínez por primera $\bigcup$ vez en la novela $A l$ filo del agua, el párroco se encuentra en el acto de rezar el Miserentr, salmo del pecador, y su actitud se expresa en la siguiente frase, que puede servir de piedra de toque en este estudio del protagonista: ". . reo él mismo y reo por su pueblo"." Por medio de este foco, se intentará ver la convincente realidad humana del hombre dentro de su metamundo literario, su instrumentalidad trágica en precipitar la tormenta que aniquila su mundo, y su posición 'central y profética dentro de la novela. Claro está que la novela no es nada simplista, y no se trata de resumirla en una sola frase; se escoge esta frase para ver sus resonancias a lo largo del libro, para dar unión al estudio del protagonista, y para sugerir las facetas múltiples de éste.

Cuando el párroco se siente, al principio de la novela reo él mismo y rco por su puablo, el sentimiento expresa un lugar común de la tradición católica en la cual el sacerdote aprende que su vocación le hace participante, dentro de su propio medio, del sacrificio del Hombre-Dios que murió reo por su pueblo. Don Dionisio vive de la tradición hispánicocatólica, y de sus normas depende su mundo entero. Este mundo es "un lugar del Arzobispado", un pueblo de mujeres enlutadas, cerrado, solemne, regido tristemente por la férrea estructura legal de la iglesia romana, sin su herencia debida de compasión, de alegría y de libertad. Es, pues, pueblo típico, y nada abstracto, del "antiguo régimen". En la seguridad de este ambiente, don Dionisio existe como párroco perfecto. A pesar de la gran posibilidad, y casi la necesidad, de hipocresía que engendran las leyes imposibles de tal sociedad, el protagonista vive en una sinceridad absoluta. Su temperamento parece compaginarse exactamente con la trap. 40.

1 Agustín Yáñez, Al filo del agua (México: Editorial Porrúa, S. A., 1963), 
dición rígida que ha sido su matriz. Es severo y solemne, austero, asceta. pero con una sola frase Yáñez libera a don Dionisio de toda la pandilla de curas antipáticos de las novelas de tesis, dándole así su autonomía:

Enjuto, alto, grandes las manos, pobladas las cejas, ralo y encanecido el cabello, el gesto severo, sin llegar a la acritud más que en casos extremos, la fisonomía denuncia lo recio del carácter y el temple de las virtudes, mayor entre las cuales emerge la caridad, hecha compasión, bien que no siendo de genio expansivo, las ejercite ocultándose, y asuman formas de rudeza cuando hay riesgo de ostentación (p. 4r).

Don Dionisio ama; "...es el hombre único singular que vive para y no por 'los demás, que nunca piensa en sí mismo".2 Así vive completamente libre su vida de obediencia, informando la austeridad con la compasión, y por eso mismo, porque puede hacerlo, no llega a comprender que los otros no son como él. Este es el primer nivel del conflicto, del agon, de don Dionisio: no puede ver las tensiones inherentes de la tradición que sirve, es incapaz de adivinar que es inhumana, que tiene que derrumbarse por su propio peso. Su razón de ser se radica en la inmutabilidad de sus creencias, que no sabe separar de la estructura que las acompaña. Su desarrollo a lo largo de la novela le lleva a experimentar la destrucción de aquella estructura que creía eterna como su fe. Al fin del libro, Yáñez le representa en un cuadro de rara belleza patética, herido en lo más hondo de su ser, derrotado, de pie entre las ruinas de su mundo, avanzando una vez más al altar de su Dios. Es el nivel del pathos, de la tragedia personal. Aquí, se hace arquetipo de una experiencia profundamente humana y perfectamente comprensible, no sólo a los que han vivido una revolución nacional, sino a todos los que hemos experimentado la muerte de Dios, la crise del foi, la noche del alma, y aun para los que vivimos sin mito ni rito, que vamos experimentando el fin del mundo moderno y la vorágine transitoria que nos lleva no sabemos si a la muerte o a la vida.

El segundo nivel tiene que ver con la "imitación de la acción", segứn la explica Fergusson en su estudio del teatro de Sófocles, y se relaciona con los mismos conceptos del rito del Enniautos-Daimon que allí aplica al Edipo. ${ }^{3}$

Siguiendo el lógico desarrollo sicológico de su protagonista, Yáñez

2 José Vázquez Amaral, "La novelística de Agustín Yáñez", Cuadernos Americanos, 1958, marzo-abril, año XVII, p. 250.

3 Francis Fergusson, The Idea of a Theater (New York, 1953), p. 39. 
mủiestrà que no es "reo" sólo en el sentido abstracto de su vocación sacerdotal, sino que actúa de instrumento inconsciente de la tormenta que destruye su rebaño. Tiene dos fallas trágicas, de las cuales no es culpable, los defectos trágicos que destruyen siempre lo que el protagonista más quiere proteger. Don Dionisio no comprende bien la condición humana (defecto de la tradición falsa que le ha producido), y no sabe mostrar ternura (defecto de temperamento y de educación). Está "al filo del agua", y no lo puede ver. Hombre hecho a la medida del antiguo régimen, no comprende que es un régimen univoco que no puede sostenerse, ni que desde fuera vienen las fuerzas opuestas, las ideas pluralistas, sobre las cuales se edificará el porvenir. Uno tras otro, sus ovejas se dejan llevar por la corriente de los tiempos. Todo se vuelve cabeza abajo conforme a que todos experimentan la erupción de las fuerzas de pasión mal reprimidas durante siglos. Luis Gonzaga Pérez, beatito neurasténico con su nombre irónicamente evocando al santo patrón de la castidad, se vuelve loco en un trastorno de deseos sexuales y de egoísmo resentido, al compás de los cantos litúrgicos del viernes santo, día de la muerte de Dios. Diametralmente opuesto a aquel triste producto de la tradición invertida, se halla Gabricl, el campanero, "el de la música encerrada", como le llama Lucas Macías, "la inocencia en varón", como le reconoce Victoria, perturbadora femenina del pueblo. Gabriel despierta súbitamente al misterio de la mujer, vive unos días de éxtasis, descompone todo el pueblo con la locura de sus campanas, pero se mantiene sano, y huye de aquella amenaza a su paraíso. Al fin, el único que puede salvarle será el párroco, y por falta de comprensión, por falta de ternura, no sabrá hacerlo. Gabriel y Luis Gonzaga, a lados opuestos del círculo, se derrotan por culpa de la misma mujer, Victoria, la victoria que ha venido desde fuera; pero el centro del círculo es don Dionisio, y en él sus vidas y sus tragedias se enredan inevitablemente. Caen Damián, Micaela, el padre Islas, cada uno reaccionando a su modo, con su propia lógica de personaje "redondo"," pero cada uno representa la pérdida del pueblo y el fracaso del párroco. Yáñez muestra esta centralidad de su protagonista en el sueño torturado que experimenta don Dionisio en la noche de Santa Cruz. Su imaginación liberada del dominio de la razón, el párroco se ve eje de la vida y de la condenación de cada uno, y en su pesadilla profética todos le repiten la misma frase: "Usted tiene la culpa". Reo él mismo, y reo por su pueblo, el inocente culpable, se despierta llorando otra variante de la misma frase:

4 Véase E. M. Forster, Aspects of the Novel (New York, 1953), pp. 67-77. 
Huic ergo parce Deus; (reo él)

Pie Jesu Domine,

Dona eis requiem. Amen (reo por su pueblo)

(pp. 207-I3)

Este sueño, además de ser técnica de unidad usada con suma maestría, parece equivaler a la peripecia de las obras del teatro. Desde aquí en adelante, don Dionisio experimenta una nueva forma de compasión, porque ha sabido desde dentro algo de lo que sufre su rebaño, y puede compadecer de veras.

Cuando llega el agua a la casa del párroco, cuando se escapa su sobrina, María, con los revolucionarios, la pesadilla se actualiza, el párroco se ve fracasado de veras, su alma molida por la realidad brutal e increíble. Correspondiendo a la pesadilla de la noche de Santa Cruz, don Dionisio tiene que contemplar su fracaso trágico a lo largo de otra noche, sin sueño esta vez:

A ninguno pudo defender. No pudo defender a Luis Gonzaga, ni a Mercedes Toledo, ni a Micaela Rodríguez, ni a Rito Becerra, ni al Padre Islas, ni a la viuda de Lucas, ni a don Timoteo, ni a Damián... Miserable pastor... ni a la oveja que traía sobre el pecho pudo salvar, antes la perdía con mayor escarnio (p. 386).

Es durante el aniquilamiento de su ser que experimenta don Dionisio durante esta noche y al acercarse al altar la mañana siguiente cuando sufre lo que atreve a llamarse el sparagmos. Porque no se trata ya de cualquier hombre con su tragedia personal a cuestas; se trata, dentro de la tradición sacerdotal de aquel "lugar del Arzobispado", de un hombre que ha sido padre, y sacerdote, llevando sobre su espíritu la responsabilidad y los sufrimientos de todos, y así perfectamente representa el héroe del Ur-myth del dios de las estaciones, y el Cristo de la cradición moderna.

Después de aquella noche de agonía, don Dionisio, reo él mismo y reo por su pueblo, entra al altar del sacrificio, al mismo altar de la misa 
cotidiana de antaño, transformado ahora en verdadero instrumento de suplicio. Es sumamente interesante que él, que al principio se nos presentó rezando el Misterere, salmo del pecador, al fin, en el momento de su fracaso y de su vergüenza, repite las palabras antiguas de esperanza y de gozo: Introibo ad altare Det: ad Deum qui ladilificat juventutem meam Fiel a su actitud de artista objetivo, Yáñez nos hace el favor de no imponer ninguna interpretación sobre estas últimas palabras, sino que nos deja la ambivalencia estética que es en este caso el toque final de la realidad humana de la novela. Las últimas palabras del protagonista pueden representar el colmo de la ironía. ¿Qué juventud, ni qué alegría se puede haber ya para el anciano vencido? Precisamente porque su mundo nunca ha podido incluir la alegria, ha sido derrumbado. Pero se ve también que el viejo no parece darse por vencido; no abandona su altar, sino aguanta, fiel a sus creencias a pesar de todo, obsesionado ya no por cuadros tétricos del Juicio Final, sino por palabras de esperanza, de juventud, de alegria. Conforme a la tesis del segundo nivel de acción del protagonista dentro del mito cristiano que propone este estudio, la última frase de la novela sugerirá la fase fina'l de la acción eterna de todos los ritos, la promesa de la resurrección.

¿Qué es, pues, lo que ha hecho don Agustín Yáñez en su novela Al filo del agtua? "Se trata", nos explica en el prólogo, "de vidas - canicas las llama uno de los protagonistas- que ruedan, que son dejadas rodar en estrecho límite de tiempo y espacio, en un pueblo de Jalisco inmediatamente antes de la revolución de I9ro". Ha escrito, claro está, una novela de la prerrevolución, pero ha hecho muchísimo más. Precisamente porque obra tan artísticamente por medio de lo limitado y lo estrechamente definido, porque se propone "solamente pintar eíl más completo retrato sicológico de sus protagonistas", halla en esta fidelidad a su materia la llave de lo universal. Ha sabido que "no importa la forma de la visión - ni su causa final- sea la belleza, la percepción, la paz, la tranquilidad, o Dios - el corazón, la substancia, y el centro de la imaginación humana, como de la vida humana, tiene que hallarse en la cosa o imagen limitada y definida". 5

Muchos mundos y muchos hombres se han encontrado "al fillo del agua". Es una verdadera experiencia humana, y Yáñez ha logrado crear en don Dionisio un personaje que los representa a todos, sin dejar de ser él, con su propio carácter y sus circunstancias "estrechas". Cuando don

5 William Lynch, Cbrist and Apollo (New Ycrk, 1963), p. 20. 
Dionisio reza, aguantando entre las ruinas de su mundo, se sitúa donde Billy Budd, donde Don Quijote, donde Edipo, cada uno a su modo, se han encontrado antes, y donde le esperan, porque a su protagonista Yáñez le ha sabido dar no sólo la "redondez" de los criterios de E. M. Forster, sino la elusiva cuarta dimensión de la universalidad.

EILEEN M. CONNOLLY

Delaware State College 